\title{
Parental relationship with children during COVID-19 lockdown in Punjab Pakistan
}

\author{
Ahmad Bilal ${ }^{\mathrm{a},}$ Saba Nawaz ${ }^{\mathrm{b}}$, Shakeela Altaf ${ }^{\mathrm{c}}$ \\ ${ }^{a}$ Assistant Professor, Department of Applied Psychology, The Islamia University of Bahawalpur. \\ ${ }^{b}$ Research Scholar, Deptartment of Applied Psychology, The Islamia University of Bahawalpur. \\ 'Scholar, Deptartment of Applied Psychology, The Islamia University of Bahawalpur. \\ *Corresponding Author's e-mail: ahmadbilal4@gmail.com
}

\section{ABSTRACT}

BACKGROUND \& OBJECTIVE: The Western studies had reported a change in parent child relationship during COVID-19 lockdown. The present study was conducted to assess the parental relationship with children during COVID-19 lockdown in Punjab province of Pakistan.

METHODOLOGY: The study involved correlational research design. 529parents from the Punjab province were recruited using a Google Form based questionnaire, which also contained information about the nature of the study and informed consent. The study was conducted from March 2020 to May 2020. The study was duly approved by Research Ethics Committee at The Islamia University of Bahawalpur vide No. REC/B/G-3/2020-S. The participants were required to give their consent for participation in the online study. The Child Parent Relationship Scale (CPRS) was appended to a single questionnaire to collect the data. The Statistical Package for the Social Sciences, version 25, was used for statistical analysis. The correlation analysis, t-test, and analysis of variance were used to compute results.

RESULTS: The study found a statistically significant positive correlation between closeness and dependence and a positive significant but weak correlation of conflict with both closeness and dependence. The mothers had more closeness and dependence with their children as compared to fathers. There were found no age wise differences in a parental relationship for conflicts, closeness, and dependence.

CONCLUSION: The study concluded that mothers had more closeness and dependence with their children as compared to fathers. Moreover, the age of parents had no effect on their relationship with children.

KEYWORDS: COVID-19, Lockdown, Pakistan, Parent Child Relationship, Punjab.

\section{INTRODUCTION}

The world witnessed a new disease Severe Acute Respiratory Syndrome-Corona Virus-2 (SARS-CoV-2), in late 2019, abbreviated as Corona Virus disease 2019 or simply COVID-19[1]. The WHO imposed a Public Health Emergency of International Concern (PHEIC) on 30th January 2020 and declared COVID-19 a pandemic on 30th March $2020^{[2]}$. As a result, many countries around the world imposed partial or complete lockdown to controll the spread of the disease through social interaction ${ }^{[3]}$.

The COVID-19 affected normal family routines ${ }^{[4]}$, and the lockdown and social distancing affected families and parent child relationships as well ${ }^{[5]}$. The parents experienced a multitude of stressors including different roles in family including supervision of children and homeschooling of children ${ }^{[6]}$ changing work dynamics and uncertainty about future $^{[7]}$. These challenges have resulted in increased on
Parental stress leading to disturbance in parental child relationships ${ }^{[8]}$.As a result, parents relationship with their children was likely to be impacted, as documented by a number of studies ${ }^{[8,9]}$.

A study done in Western Saudi Arabia with 377 parents revealed that COVID-19 quarantine decreased conflict between parents and children,especially mothers who spent more time with their children ${ }^{[5]}$. There was no gender difference in closeness during the COVID-19 lockdown period between parents and children ${ }^{[5]}$.

A study conducted on parent-child relationships during the outbreak of H1N1 flu during 2009 reported that social isolation caused parental distress, which impacted their relationship with children ${ }^{[10]}$.

Recently, another study was conducted with 355 parents living in Lahore to assess the impact of COVID-19 pandemic on parental stress and parent child relationship.

Bilal A, Nawaz S, Altaf S. Parental relationship with children during COVID-19 lockdown in Punjab Pakistan. Journal of Univesristy Medical \& Dental College.2021;12(4):248-251. 
The results reported that around $93 \%$ of parents spent more time with their children, and $67 \%$ parents reported being close to their children during period of lockdown. On the other hand, parents also reported more than usual use of disciplinary activities such as $72 \%$ of parents shouted, or yelled at their children, 58\% took away children' privileges, and around $35 \%$ of parents spanked or slapped their children at least once during the past 1 month $^{[11]}$.

Although, studies are being conducted to explore the impact of COVID-19 pandemic on parent child relationships, there is stilla considerable gap in the literature on parent child relationship during COVID-19 related lockdown ${ }^{[12,13]}$. This is so as the majority of studies had been conducted in Western countries. The Pakistani parents have cultural differences from their Western counterparts, so indigenous studies are needed to understand the parent child relationship during COVID-19 lockdown in Pakistan. At present, there had been found only 1 study conducted with Pakistani parents living in Lahore. Therefore, the present study was designed with an aim to find out the fathers and mothers relationship with their children during COVID-19 lockdown in Punjab province of Pakistan. Moreover, the study aimed to find out the gender differences in parent child relationship and the impact of parents' age on their relationship with children.

\section{METHODOLOGY}

The correlational research design was used in this study. The study was conducted from March 2020 to May 2020 at Bahawalpur. The data was collected by using Google Forms which was distributed all over Punjab through social media platforms. Five hundred and twenty-nine parents from all over Punjab participated in the study. The sample size was calculated using Survey monkey sample size calculator with a 95\% confidence interval and 5\% margin of error ${ }^{[14]}$ for a population of 110012442 as per the 2017 Census $^{[15]}$. The sample size was significantly inflated to 529 parents instead of 385 parents to increase the authenticity and generalizability of findings. A significant increase had been observed in father children relationship recently apart from the traditional mother child relationship ${ }^{[16]}$, so fathers were also included in the study. A low number of mothers could be included in the sample because of cultural reasons. The written informed consent was appended to the Google Form giving information about the nature of study. The participants were required to read and agree to the Informed Consent before filling the questionnaire. The parents living in Punjab province who had internet access were included in the study, while parents from other provinces of Pakistan or those having no internet access were excluded from the study. The parents living in the Punjab province who had internet access were included in the study as the Punjab province is the most populated province of Pakistan, and there was the first wave of COVID-19 lockdown in Pakistan, so the data collection through physical interaction was not feasible.
The Child Parent Relationship Scale (CPRS) was appended to a single questionnaire containing informed consent to collect the data. Each participant was required to fill the whole questionnaire in 35 minutes. The CPRS is a 30 item likert type scale that measures the 3 aspects of child parent relationships, namely conflicts, closeness, and dependence on a likert scale of 1 (definitely does not apply) to 5 (definitely applies). Higher scores on the scale represent a high score on that particular aspect. The scale has Cronbach Alpha reliability of $.83, .72$, and .50 for conflict, closeness, and dependence subscales, respectively ${ }^{[17]}$.

The study was duly approved by the Research Ethics Committee of the Department of Applied Psychology at the Islamia University of Bahawalpur vide No. REC/B/G$3 / 2020-\mathrm{S}$. The data was analyzed by the Statistical Package for the Social Sciences, v 25. The skew and kurtosis values for the data were normally distributed so parametric statistics were used to analyze data. The data was analyzed by correlation analysis, t-test, and analysis of variance (ANOVA). The value of $\mathrm{p}<.05$ was taken as significant.

\section{RESULTS}

There are 529 participating parents in the study. Around $491(93 \%)$ are fathers, while only $7(7 \%)$ are mothers. The majority,405 $(77 \%)$ parents, were from the age group of $31-$ 40 years, followed by 67 (13\%) were of or below 30 years and $57(11 \%)$ from the age group of 41-50 years.

Table-I: Correlations among Conflicts, Closeness, and Dependence $(\mathbf{n}=529)$.

\begin{tabular}{ccccc}
\hline & & Conflicts & Closeness & Dependence \\
\hline Conflicts & $\mathrm{r}$ & 1 & $0.18^{* *}$ & $0.26^{* *}$ \\
& $\mathrm{p}$-value & - & $<0.001$ & $<0.001$ \\
Closeness & $\mathrm{r}$ & $0.18^{* *}$ & 1 & $0.53^{* *}$ \\
& $\mathrm{p}$-value & $<0.001$ & - & $<0.001$ \\
Dependence & $\mathrm{r}$ & $0.26^{* *}$ & $0.53^{* *}$ & 1 \\
& $\mathrm{p}$-value & $<0.001$ & $<0.001$ & - \\
\hline
\end{tabular}

$* * \mathrm{p}<0.001$

The table-I gives the correlation among conflict, closeness, and dependence. The closeness was statistically significantly correlated with dependence $(\mathrm{r}(527)=.53, \mathrm{p}<0.001)$. There is a weak positive significant correlation of conflicts with closeness $(\mathrm{r}(527)=.18, \mathrm{p}<0.001)$ and dependence $(\mathrm{r}(527)=.26, \mathrm{p}<0.001)$.

Table-II provides results of t-test computed to find out gender based differences in parents for conflicts, closeness, and dependence. The results are statistically significant for both closeness and dependence. There are significant differences in mothers and fathers on closeness and dependence $(\mathrm{t}(44.67)=-8.89, \mathrm{p}<.05)$; and $(\mathrm{t}(527)=-5.51, \mathrm{p}<.05)$.

The mothers scored high on both variables $(\mathrm{M}=42.47$, $\mathrm{SD}=6.45$ vs $\mathrm{M}=32.70, \mathrm{SD}=7.30)$; and $(\mathrm{M}=16.13, \mathrm{SD}=2.83$ vs $\mathrm{M}=13.41, \mathrm{SD}=2.92$ ) respectively. 
Bilal A, Nawaz S, Altaf S, et al.,

Table-II: Comparison of child parent relationship between father and mother.

\begin{tabular}{|c|c|c|c|c|c|}
\hline \multirow[b]{2}{*}{ Variables } & \multirow[b]{2}{*}{ Mean \pm SD } & \multicolumn{2}{|c|}{ Gender of Parent } & & \multirow{2}{*}{$\begin{array}{c}\text { p-value } \\
\text { Sig. }\end{array}$} \\
\hline & & Mean \pm SD & $\mathbf{t}$ & df & \\
\hline Conflicts & $36.93 \pm 6.19$ & $38.94 \pm 9.16$ & -1.33 & 39.66 & 0.19 \\
\hline Closeness & $32.70 \pm 7.30$ & $42.47 \pm 9.16$ & -8.89 & 44.67 & $<0.001$ \\
\hline Dependence & $13.41 \pm 2.92$ & $16.13 \pm 2.83$ & -5.51 & 527 & $<0.001$ \\
\hline
\end{tabular}

The mothers scored high on both variables( $\mathrm{M}=42.47, \mathrm{SD}=6.45 \mathrm{vs} \mathrm{M}=32.70, \mathrm{SD}=7.30)$; and $(\mathrm{M}=16.13, \mathrm{SD}=2.83 \mathrm{vs} \mathrm{M}=13.41$, $\mathrm{SD}=2.92$ ) respectively.

Table-III: Comparison of child parent relationship between different age groups using analysis of variance $(\mathrm{n}=529)$.

\begin{tabular}{ccccccc}
\hline Age Groups (years) & $\mathbf{3 0 y}(\mathbf{n}=\mathbf{6 7})$ & $\mathbf{3 1 - 4 0 y}(\mathbf{n}=\mathbf{4 0 5})$ & $\mathbf{4 1 - 5 0 y}(\mathbf{n}=\mathbf{5 7})$ & $\mathbf{F}(\mathbf{2})$ & $\mathbf{p}$-value \\
\hline Variables & Mean \pm SD & Mean \pm SD & Mean \pm SD & & & \\
Conflicts & $36.16 \pm 6.76$ & $37.35 \pm 6.40$ & $36.15 \pm 6.42$ & 1.62 & 0.19 \\
Closeness & $33.38 \pm 6.76$ & $33.68 \pm 6.40$ & $31.49 \pm 7.12$ & 2.04 & 0.13 \\
Dependence & $13.62 \pm 6.76$ & $13.73 \pm 3.01$ & $12.77 \pm 2.82$ & 2.56 & 0.07 \\
\hline
\end{tabular}

Table-III gives the results of analysis of variance (ANOVA) computed to find out age wise differences in conflicts, closeness, and dependence. The results are not statistically significant for all variables so there are no significant differences in conflicts, closeness and dependence across all age groups $(F(2)=1.62, p>05) ;(F(2)=2.04, p>.05)$; and $(F(2)=2.56, p>.05)$ respectively.

\section{DISCUSSION}

The present study was conducted with an aim to find out the parental relationship with children during times of COVID-19 related lockdown in Punjab province of Pakistan. The results revealed that mothers were high on both closeness and dependence as compared to fathers. It is understandable and in line with the common practice in our culture where children usually spend more time with their mothers and mothers care for the children more often as compared to fathers. The present study showed the positive side of COVID-19 related lockdown. The earlier study conducted with Pakistani parents living in Lahore also reported the positive impact of COVID-19 lockdown [11] whereas the previous studies only focused on the negative consequences of COVID-19 related lockdown ${ }^{[18,19]}$.

A study by Gambin et al., found that COVID-19 quarantine and social isolation brought closeness between parents and their children. It may be due to spending more time together or focusing parents on their children's needs during times of crisis ${ }^{[9]}$. This study also validated the role of mothers in bringing positive experiences and closeness. It is because children in our culture generally spent more time with their mothers and mothers are generally characterized by more empathy and parenting self efficacy, which directly contributed to positive experiences and closeness with the children ${ }^{[9]}$.

On the other hand, there was found no significant difference in conflicts between fathers and mothers. Both parental figures were found to show conflicts equally with their children. Moreover, there were found a positive relationship between closeness and dependence whereas there was also
Staying at home and spending more time with children not only strengthened closeness and dependence ties between parents and children but it also increased conflicts ${ }^{[5,11]}$.

The present study did not find any significant difference in conflicts, closeness, and dependence across age groups of parents. No age group was found significantly vulnerable to have more conflicts, closeness, and dependence with their children. All age groups of parents experienced similar levels of conflicts, closeness, and dependence. This is in line with the results of Uzun et al. which reported that age did not predict parent child relationship for fathers ${ }^{[20]}$.

\section{CONCLUSION}

The present study concludes that mothers had high levels of closeness and dependence with their children compared to fathers. The age of the parents had no effect on parent child relationship during COVID-19 lockdown.

LIMITATIONS:

The study sampledonly those parents who had internet access and were living in Punjab province. Thus, the study's results are not generalizable throughout Pakistan. Moreover, the present study did not include children in the sample.

\section{RECOMMENDATIONS:}

The study can be furthered by including parents from all over Pakistan. The analysis of the parent child relationship can be enriched by including relevant demographic variables.

\section{ACKNOWLEDGEMENT:}

We are indebted to parents in Punjab province for sparing their precious time for participation in this study. Without their contribution, this study had not been possible. 


\section{CONFLICT OF INTEREST:}

All authors declare no conflict of interest.

\section{GRANT SUPPORT \& FINANCIAL DISCLOSURE: None}

\section{REFERENCES:}

1. World Health Organization. Coronavirus disease (COVID-19). [cited 2020 September 4]. Available from:https://www.who.int/emergencies/diseases/novelcoronavirus-2019

2. World Health Organization. Statement on the second meeting of the International Health Regulations (2005) Emergency Committee regarding the outbreak of novel coronavirus (2019-nCoV). Published 2020 January 30 [cited 2020 December 12]. Available from: https:// www.who.int/news-room/detail/30-01-2020-statementon-thesecondmeeting-of-the-international-healthregulations-(2005)-emergencycommittee-regardingthe-outbreakof-novel-coronavirus-(2019-ncov).

3. Wilder-Smith A, Freedman DO. Isolation, quarantine, social distancing and community containment: pivotal role for old-style public health measures in the novel coronavirus (2019-nCoV) outbreak. Journal of travel medicine. 2020; 27(2): taaa020. Doi: 10.1093/jtm/ taaa020.

4. Brown SM, Doom JR, Lechuga-Peña S, Watamura SE, Koppels T. Stress and parenting during the global COVID-19 pandemic. Child Abuse \& Neglect. 2020;110:104699.

5. Andejany N, Qutah K, Alwajeeh S, Msallam R, Alyamani D. Parent Child Relationship During COVID-19 in SaudiArabia. [preprint]. Research Square:2020.Doi:10.21203/rs.3.rs-93850/v1

6. Ones L. The COVID-19 pandemic: A family affair. Journal of family nursing. 2020;26(2):87-89. Doi:10.1177/1074840720920883.

7. Coyne LW, Gould ER, Grimaldi M, Wilson KG, Baffuto G, Biglan A. First things first: parent psychological flexibility and self-compassion during COVID-19. Behavior Analysis in Practice. 2020:1-7. Doi10.31219/ osf.io/pyge2.

8. Riegler LJ, Raj SP, Moscato EL, Narad ME, Kincaid A, Wade SL. Pilot trial of a telepsychotherapy parenting skills intervention for veteran families: Implications for managing parenting stress during COVID-19. Journal of Psychotherapy Integration:2020; 30(2):290-303. Doi:10.1037/int0000220.

9. Gambin M, Woźniak-Prus M, Sekowski M, Cudo A, Pisula E, Kiepura E, et al. Factors related to positive experiences in parent-child relationship during the COVID-19 lockdown. The role of empathy, emotion regulation, parenting self-efficacy and social support.2020: 1-11. Doi:10.31234/osf.io/yhtqa.

10. Sprang G, Silman M. Posttraumatic stress disorder in parents and youth after health-related disasters. Disaster Medicine \& Public Health Preparedness: 2013;7: 105110. Doi:10.1017/dmp.2013.
11. Imran N, Sharif MI, Iqtadar S, Javed A, Azeem MW. Parental Stress and Parenting during COVID-19 Pandemic in Pakistan. World Social Psychiatry. 2021;3(1):30-35. Doi:10.4103/wsp.wsp_73_20.

12. Brooks SK, Webster RK, Smith LE, Woodland L, Wessely S, Greenberg N, et al. The psychological impact of quarantine and how to reduce it:rapid review of the evidence. The Lancet: 2020; 395(10227): 912920. Doi:10.1016/S0140-6736(20)30460-8.

13. Prime H, Wade M, Browne DT. Risk and resilience in family well-being during the COVID-19 pandemic. American Psychologist. 2020;75(5):631-634. Doi:10.1037/amp0000660.

14. Survey Monkey. Survey Size Calculator. [cited 2020 February 28]. Available from: https://www. surveymonkey.com/mp/sample-size-calculator.

15. Pakistan Bureau of Statistics. Population Census. Published 2018 January 03. [cited 2020 December 14]. Available from: http://www.pbs.gov.pk/content/ population-census.

16. Alon T, Doepke M, Olmstead-Rumsey J, Tertilt M. The impact of COVID-19 on gender equality. National Bureau of economic research; 2020.

17. Driscoll K, Pianta RC. Mothers' and Fathers' Perceptions of Conflict and Closeness in Parent-Child Relationships during Early Childhood. Journal of Early Childhood \& Infant Psychology. 2011; 1(7):1-24.

18. Chung G, Lanier P, Wong PY. Mediating effects of parental stress on harsh parenting and parent-child relationship during coronavirus (COVID-19) pandemic in Singapore. Journal of family violence. 2020:1-2. Doi:10.1007/s10896-020-00200-1.

19. Cluver L, Lachman JM, Sherr L, Wessels I, Krug E, Rakotomalala S, et al. Parenting in a time of COVID-19. Lancet. 2020;395(10231). Doi:10.1016/ S0140-6736(20)30736-4.

20. Uzun H, Karaca NH, Metin Ş. Assesment of parent-child relationship in Covid-19 pandemic. Children and Youth Services Review. 2021;120:105748. Doi:10.1016/j. childyouth. 2020.105748

\section{Author's Contribution:}

Ahmad Bilal: Conception and design, revising it critically for intellectual content..

Saba Nawaz: Acquisition of data, interpretation of data, final approval.

Shakeela Altaf: Acquisition of data, Analysis of data and drafting the article.

Submitted for Publication:23-03-2021 Accepted after revision: 20-10-2021 